\title{
Behavior of cows during and after peak feeding time on organic and conventional dairy farms in the United Kingdom
}

\author{
F. M. Langford, ${ }^{1}$ K. M. D. Rutherford, L. Sherwood, M. C. Jack, A. B. Lawrence, and M. J. Haskell \\ Animal Behaviour and Welfare, Sustainable Livestock Systems, Scottish Agricultural College, West Mains Road, Edinburgh, EH9 3JG, \\ United Kingdom
}

\begin{abstract}
The behavior of groups of housed, lactating dairy cattle was observed over 2 winter housing periods on 20 organic farms and 20 conventional farms in the United Kingdom. Three methods were used: (1) 6 video-clips of 10 min duration were captured of cows feeding at sections of the feed-bunk face during the peak feeding period (0 to $90 \mathrm{~min}$ ) and continuously observed for aggressive interactions among cows; (2) the proportion of cows at the feed-bunk face was scanned every $15 \mathrm{~min}$ for $4.5 \mathrm{~h}$ to include the peak feeding period (0 to 255 min); and (3) all nonfeeding behaviors were scanned every $15 \mathrm{~min}$ for $2.5 \mathrm{~h}$ after the peak feeding period (120 to $255 \mathrm{~min}$ ). The latter scans were analyzed post hoc for measures of cow comfort (freestall farms only). Management and health data were collected on each farm. On farms with open-fronted feed-bunk faces, a greater number of aggressive interactions occurred at the feed-bunk face at peak feeding time on organic farms than on conventional farms (organic $=36.3 \pm$ 4.4 ; conventional $=29.1 \pm 3.0$ ). Higher proportions of cows were at the feed-bunk face at peak feeding on organic farms than on conventional farms (organic $=$ $0.58 \pm 0.04$; conventional $=0.48 \pm 0.03)$. Housing type (freestall versus straw pen) explained most differences in postfeeding behavior (proportion of ruminating cow in alleyways: freestalls $=0.16 \pm 0.06$ vs. straw-pen $=$ $0.08 \pm 0.03)$, with few differences between organic and conventional herds. On freestall farms, the proportions of cows on organic farms lying down postfeeding was smaller than in conventional herds (organic $=0.38 \pm$ 0.09 vs. conventional $=0.43 \pm 0.07)$. Differences in behavior around peak feeding time could be associated with the reduction in food "quality" on organic farms compared with the energy requirement of the cows, with cows on organic farms being highly motivated to feed. A correlation was observed between farms that had high amounts of lying and farms that had high
\end{abstract}

Received March 31, 2010.

Accepted October 8, 2010.

${ }^{1}$ Corresponding author: fritha.langford@sac.ac.uk lameness prevalence $\left(\mathrm{R}^{2}=55.3\right)$, suggesting a complex relationship between comfort and pain. Overall, the behavior of dairy cows on organic farms was not different from that of conventionally reared cows, and the results suggest that most behavioral welfare problems relating to housing could be alleviated by management practices.

Key words: dairy cow, behavior, organic production

\section{INTRODUCTION}

Organic produce appeals to consumers who are concerned about their health, the effect of farming on the environment, and animal welfare (Harper and Makatouni, 2002; Yiridoe et al., 2005). There are concerns that, in practice, some of the regulations governing organic milk production may compromise animal welfare (Weller and Bowling, 2000; Hovi et al., 2003; Vaarst et al., 2005). One particular concern is about the use of high-yielding breeds (such as the Holstein-Friesian) in organic dairying, as it is thought that high-yielding animals are more sensitive, in terms of health, to inadequate DMI (quantity and quality; Sundrum, 2001). Cows on organic farms are fed foodstuffs grown without pesticides or fertilizers. During this study, UK regulations dictated that farmers provide between $90 \%$ (in 2003 ) and 95\% (in 2005) of all feed from organic sources (100\% from 2007) and that the proportion of DMI fed as concentrate was restricted to $40 \%$. These changes in quality of feed given to cows on organic farms can affect energy balance if DMI is insufficient (Thompson, 2008) and, therefore, has the potential to alter cows' motivation to feed and associated behaviors.

Additionally, different regulations apply to housing standards for organic farms. Organic livestock farming in the UK comes under a European Commision Regulation (2092/91), which specifies that disease prevention be primarily based on management systems that promote resistance to disease and recovery from infection (CEC, 2004). The quantity and quality of the housing space can be one of the factors that affect an individual cow's ability to access and maintain resources such as lying and feeding areas (Huzzey et al., 2006). 
The objective, as part of a larger overall project investigating the welfare of cows on organic and conventional farms, was to ascertain if differences between the farm types affect aggression and comfort during and after peak feeding time. This study focused on the behavior of cows that has the potential to be most affected by the main differences in regulations between the farm types; that is, motivation to access feed and cow comfort.

\section{MATERIALS AND METHODS}

\section{Recruitment and Farm Selection}

Twenty organic and 20 conventional farms throughout the UK (13 farms in southwestern Scotland, 25 farms in western England, 2 farms in Wales) were visited during 2 winters (2004-2005 and 2005-2006). Dairy farmers on organic farms were recruited from the membership lists of organic producer groups (Organic Milk Suppliers Co-Operative, Worle, Somerset, UK; Scottish Organic Producers Association, Edinburgh, UK), and an organic certifier (The Soil Association, Bristol, UK). Details of the recruitment process for organic and conventional farms can be found in Rutherford et al. (2008). The farms were limited to those that had predominantly Holstein-Friesian cows and a mature herd size of $>50$ cows. All farms grazed for at least part of the summer period and housed their cows during the winter. All farms milked their cows twice daily in the morning and afternoon. The organic farms had been certified as organic for at least $2 \mathrm{yr}$ before the start of the study to minimize the effects of conversion.

Once an organic farm was recruited, a matching conventional farm was sought. The criteria upon which a matching farm was selected were housing type (freestall or straw pen), herd size, genetic merit, and as far as possible, location within the UK, taking into account local rainfall profiles. Thirteen pairs of freestall farms and 7 pairs of straw pen farms were recruited. The median (and first and third quartile) milking herd size was 156 cows (97 to 184) on the organic farms and 151 cows (117 to 194) on conventional farms. The median production per cow in 2004 was $7,200 \mathrm{~kg}(6,059$ to 8,773$)$ on organic farms and $8,521 \mathrm{~kg}(6,789$ to 9,219$)$ on conventional farms. Matched pairs of organic and conventional farms were visited within a 2 -wk period during winter housing. All farms housed their cows for at least 1 mo before the visit; each farm visit lasted $2.5 \mathrm{~d}$.

\section{Supplementary Information Gathered On Farm}

Each farmer was asked to provide the following information regarding the feeding of their cows: the $\mathrm{ME}$ of the first cut of silage for the study year, the amount of forage fed per cow/year, the amount of concentrates used per cow/year, and the concentrate constituents. A building audit, which involved the collection of a wide selection of building measurements (freestall dimensions, feed-bunk face length, height, head-space, type and number of feed-bunk faces, area of alleyways, flooring type, and alleyway scraping frequency), was carried out on the winter housing of the lactating cows (Langford et al., 2009). Additionally, the following animal-based health and welfare measures were scored on the farm visits: lameness prevalence and BCS (Rutherford et al., 2009a,b). The feeding information, building measurements, lameness prevalence, and BCS farm averages were used as univariate measures in the process of building the statistical models for predicting the proportions of animals at the feed-bunk face and the postfeeding behavior as explained below.

\section{Behavioral Observations}

Behavioral observations were carried out on 2 consecutive mornings of the farm visit. On farms where all lactating cows were housed in one group, all cows were sampled. On farms where the groups were split by lactation stage, only the early lactation group was sampled. The numbers of individual cows in the groups were noted.

Behavioral observations on all farms commenced when new feed became available to the cows after the morning milking. On some farms (organic $=6$; conventional $=7$ ), new feed was available to cows exiting the milking parlor, meaning that cows milked early were able to access food before cows milked later in the milking process. In these cases the behavioral observations began when approximately $75 \%$ of the herd had exited the milking parlor. This time point is referred to herein as time zero, and it varied from 0550 to $1120 \mathrm{~h}$.

\section{Proportions of Cows at the Feed-Bunk Face}

The feeding areas were split into equal sections approximately $2.5 \mathrm{~m}$ long by visually marking the sections with chalk. All feeding areas were included. The median number of sections was 10 (7 to 16 ). On 29 farms this was 1 side or 2 sides of a feed-passage or feed-bunk. On 11 farms a variety of feeding devices was available, including troughs; free-standing feeding rings; portable, free-standing rectangular feeders with metal head-spaces for cows that were filled with silage or TMR; and areas where cows could self-feed from silage bunker silos. Each section, either part of a feedpassage or part of a free-standing trailer, was numbered in a consecutive manner, traveling clockwise around the 
Table 1. Ethogram used to score aggressive interactions at the feed-bunk face

\begin{tabular}{ll}
\hline Term & Observed behavior \\
\hline Head butt & The actor uses head to head or head to body contact in an attempt to physically displace the recipient \\
Push & The actor uses some part of the body other than the head to displace the recipient \\
Penetrate & The actor pushes with force between 2 feeding cows at the feed-bunk face resulting in physical contact with cows on both sides \\
Bulldoze & The actor forcefully enters the front of the feed-face displacing more than one individual \\
Withdrawal & The recipient withdraws the head from feed-bunk face and moves into passageway to escape from the actor \\
\hline
\end{tabular}

feeding areas from a starting point close to the parlor exit. Whether the feed-bunk face was of an open design or had individual head locks was recorded. The number of cows feeding at all of the feed-bunk face sections was counted by instantaneous scan sampling every $15 \mathrm{~min}$ for $4.5 \mathrm{~h}$ from time zero for a total of 18 observations. Therefore, every $15 \mathrm{~min}$ the observer would start at section 1 and count all of the cows in each section, traveling clockwise until all of the sections had been counted. This took between 1 to 5 min depending on the number of sections and the arrangement of the feeding area. For simplicity, cows were counted as "feeding" when they had their head through the feed bunk face barrier. Because of the speed and ease of the counting, the number of cows counted twice was minimized. These numbers were used to ascertain the total proportion of animals feeding throughout the $4.5 \mathrm{~h}$ of observations.

\section{Observations of Behavior at the Feed-Bunk Face}

On farms where a clear view of the feed-bunk face could be filmed using a digital video camera, six 10-min video clips were made of interactions between cows at the feed-bunk face. These clips were made in between each of the first 7 feeding scans as detailed above, resulting in video clips of 10 min with a 5 -min gap from 5 min post-time zero until 90 min post-time zero. Farms with extremely complex feeding arrangements and any with self-feed silage bunker silos were not filmed. This restriction meant that aggressive interactions were sampled on 31 of the 40 farms (14 organic, 17 conventional). The 2.5-m sections of the feed-bunk face were numbered consecutively (detailed above). The median number of sections was 12 (8 to 17). Six numbered sections of feed-bunk face were chosen at random from the total. Ten minutes of video of the feed-bunk face were recorded from each of the chosen sections in a random order (Mini DV digital tapes, JVC Japan, Tokyo, Japan; XM2 digital video recorder, Canon, Tokyo, Japan). Three limiting conditions prevailed: if the section contained fewer than 3 cows feeding at the start of the clip, if a section was obscured from view, or if the section contained no feed it was discounted. When sections were rejected, another section was chosen at random. Cows could leave the section during filming, but the section was filmed for the entirety of the 10 min. Each chosen section of the feed-bunk face was filmed such that the head of each feeding cow was visible to the camera.

Aggressive interactions between cows were quantified by observation of the tapes. The tapes were all observed by 1 trained observer. Behavior was analyzed using continuous sampling of all cows present in the section filmed. The number of animals feeding in the section at the beginning of the sampling period was noted. Arrival, departure (by a cow's own choice), or withdrawal (after an interaction with another cow) of any cow during the sampling period was recorded. Aggressive interactions between cows were recorded and classified using a simple ethogram (Table 1). This method of sampling aggressive behavior at the feed-bunk face was validated against continuous observation with focal cows and was correlated $(\mathrm{R}=0.75, P<0.001 ; \mathrm{J} . \mathrm{M}$. Gibbons, F. M. Langford, and M. J. Haskell of Animal Behavior and Welfare, Scottish Agricultural College, Edinburgh, UK,, unpublished data).

\section{Observations of Behavior After Peak Feeding}

Two hours after time zero, instantaneous scans of all of the behaviors by the group of cows began and were then taken every 15 min for $2.5 \mathrm{~h}$ (10 scans). A hierarchical ethogram was used detailing where the cow was in the building (e.g., freestalls, freestall alleyways, straw pen, feed-bunk face alleyways), her posture, and her behavior (Table 2). The number of cows performing each type of behavior was recorded for each time point.

\section{Post Hoc Analysis of Behavior}

Four indices were used to assess the quality of the freestalls: stall occupancy, cow comfort index, stall use index, and stall perching index (Cook et al., 2005). These scores were applied to the 13 pairs (organic/ conventional) of freestall facilities.

\section{Statistical Analyses}

Genstat (Genstat, 8th ed., Lawes Agricultural Trust, VSN International Ltd., Oxford, UK) was used for all statistical analyses. Comparisons of feed-bunk face di- 
Table 2. Hierarchical ethogram used to record behavior of cows after peak feeding

\begin{tabular}{llll}
\hline Location & Posture & Behavior & Description of behavior \\
\hline Feed-bunk face & Standing & Idling & Not performing any other behavior \\
Alleys & Lying & Ruminating & Rhythmic chewing of the cud \\
Bedded area & Standing half-in ${ }^{1}$ & Sleeping & Eyes closed, ears down, neck muscles relaxed \\
& & Feeding & Ingestion of food \\
& Drinking & Intake of water from a water trough \\
& Grooming & Licking or scratching body or head \\
& Walking & Walking \\
& Mounting & One cow stands on rear legs resting front legs and body on the back of another cow \\
\hline
\end{tabular}

${ }^{1}$ This posture could be scored in freestalls only.

${ }^{2}$ This behavior could only be scored when the cow was lying down.

mensions were made using 2-sample $t$-tests for normally distributed data and the Mann-Whitney test for data that was not normally distributed. Counts of aggressive interactions were analyzed using a generalized linear mixed model (REML with fixed fitting method) fitted using a Poisson distribution (using a logarithm link function). Feed-bunk face per cow and all interactions between farm type and feed-bunk face type were the fixed effects. The farm and time were fitted as the random effects.

Proportions of cows at the feed-bunk face, herd behavior data, and the post hoc tests were analyzed using multi-factor REML variance components analysis with an average information optimization method fitted to the Poisson data (using a logarithm link function). Data on feeding amounts and methods, measurements made of the farm buildings and cow resources, and herd-level lameness and BCS were all used as possible explanatory variables. Preliminary univariate analyses were undertaken with each explanatory variable to identify those to be used in the multi-factor models: any variables where the Wald statistic was significant at $P<0.25$ were then considered in multi-factor models. The interactions between farm and time were fitted as the random effects with an auto-regressive structure of the covariance model (i.e., scans 1 and 2 were more closely correlated than scans 1 and 10) to account for the repeated structure of the data.

Models were built using a forward stepwise selection technique, adding in each explanatory variable to the fixed effect model. Explanatory variables with the lowest $P$-value from the univariate analyses were added first. Variables within the final model were chosen based on their additional significance when all other explanatory variables in the model had been fitted (i.e., on the adjusted sum of squares). Spearman rank correlations were used to identify relationships between explanatory variables. This process eventually led to models that remained stable regardless of variable order. Only explanatory variables that were present in the final mod- els are presented in the results. The back-transformed adjusted means are presented in the results tables.

\section{RESULTS}

\section{Proportions of Cows at the Feed Face}

In total, 23 farms (10 organic, 13 conventional) had open feed-bunk faces and 15 farms (8 organic, 7 conventional) with head-lock type barriers (these include both the locking and nonlocking barriers with headspaces for cows, all barriers remained unlocked during behavioral observations). Two organic farms had selffeed silage bunker silos. Feed-bunk face length did not differ between farm types (mean $\pm \mathrm{SE}$, organic $=49.7$ $\pm 6.6 \mathrm{~m}$; conventional $=56.5 \pm 4.0 \mathrm{~m}, t=-0.9 ; P>$ 0.05). Conventional farms had larger group sizes than organic farms (median and interquartile range: organic $=74.5,53$ to $96 ;$ conventional $=101.5,74$ to 136 Wald $=270 ; P<0.05)$. Feed-bunk face length per cow was not different between farm types (organic $=0.62 \pm$ $0.05 \mathrm{~m}$; conventional $=0.56 \pm 0.04 \mathrm{~m}, t=0.8, P>$ $0.05)$. The number of farms that fed concentrates in the parlor during milking did not differ with farm type (12 organic and 14 conventional farms). Genetic merit of the cows for milk factors (profit index) did not differ between farm types (median, organic $=20,18$ to 25.5; conventional $=21,19$ to 26.7 , Wald $=756 ; P>0.05$ ).

Farm type (organic vs. conventional), feed-bunk face type, and feed-bunk face space per cow had no effect on the proportion of animals feeding following new food arrival when the entire $4.5 \mathrm{~h}$ time was considered (all $P>0.05)$. Minutes since time zero had a significant effect on the proportion of cows feeding, from $>0.55$ \pm 0.03 between 0 min and 45 min after the arrival of new food, to $0.30 \pm 0.02$ after 240 min post-time zero (Figure 1). The first $90 \mathrm{~min}$ after new feed was available were analyzed separately, to correspond with the time used in the aggressive social interaction analysis. A higher proportion of cows from organic farms than cows from conventional farms were feeding during this 


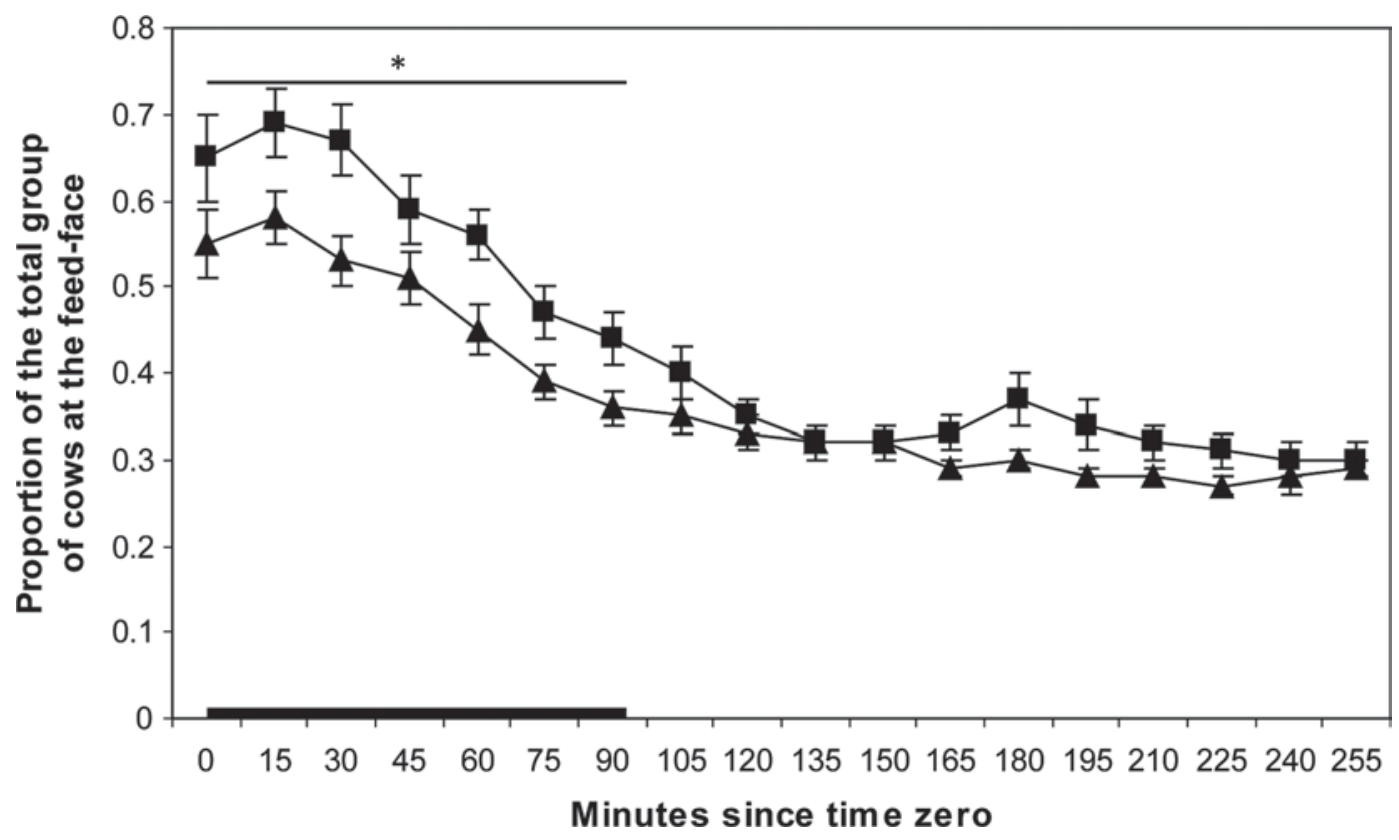

Figure 1. The mean $( \pm \mathrm{SE})$ proportion of cows feeding at each of the behavioral scans taken every 15 min after the arrival of new food after the morning milking (time zero) on organic $(\mathbf{\square})$ and conventional $(\boldsymbol{\Lambda})$ farms. Proportions of cows feeding differ over time $($ Wald $=12.91, P<$ 0.001). Farm-type differences are seen during the first $90 \mathrm{~min}$ of feeding after time zero (black bar; Wald $=4.28, P<0.05)$. The asterisk $(*)$ indicates significance at $P<0.05$.

period $($ organic $=0.58 \pm 0.04 ;$ conventional $=0.48 \pm$ $0.03 ;$ Wald $=4.28 ; P<0.05)$.

\section{Aggressive Interactions at the Feed-Bunk Face at Peak Feeding}

As types of aggressive behaviors were highly variable in relative frequency, all aggressive actions were counted together for the statistical analysis. A greater numbers of aggressive interactions occurred between cows at the feed-bunk face on farms with open barrier designs compared with head-lock barriers (open feed face $=32.2 \pm 2.6$, head-lock feed face $=17.8 \pm 1.2$; Wald $=21.1 ; P<0.001)$. Farm type had no effect on the numbers of aggressive interactions (organic $=$ $27.0 \pm 3.2$, conventional $=23.5 \pm 2.5 ;$ Wald $=1.27 ;$ $P>0.05)$. A significant interaction occurred between farm type and feed-bunk face type (Wald $=4.65 ; P<$ 0.05; Figure 2). On farms that had head-lock barrier feed-bunk faces, farm type had no effect on the numbers of interactions between cows $(P>0.05)$. On farms that had open barrier feed-bunk faces, cows on organic farms had a greater number of aggressive interactions than cows on conventional farms (organic $=36.3 \pm 4.4$; conventional $=29.1 \pm 3.0$, Wald $=3.85 ; P<0.05)$.

\section{Nonfeeding Behavior of Cows Post-Peak Feeding}

Overall, not many differences were found between organic and conventional cows in nonfeeding behavior.
Housing type had a greater effect on behavior than did farm type: a greater proportion of cows housed in freestalls were ruminating (standing) in the alleyways than those on straw (freestalls $=0.16 \pm 0.06$, straw pen $=$ $0.08 \pm 0.03$, Wald $=3.01 ; P<0.05)$. For most analyses, housing types were considered separately. Freestall

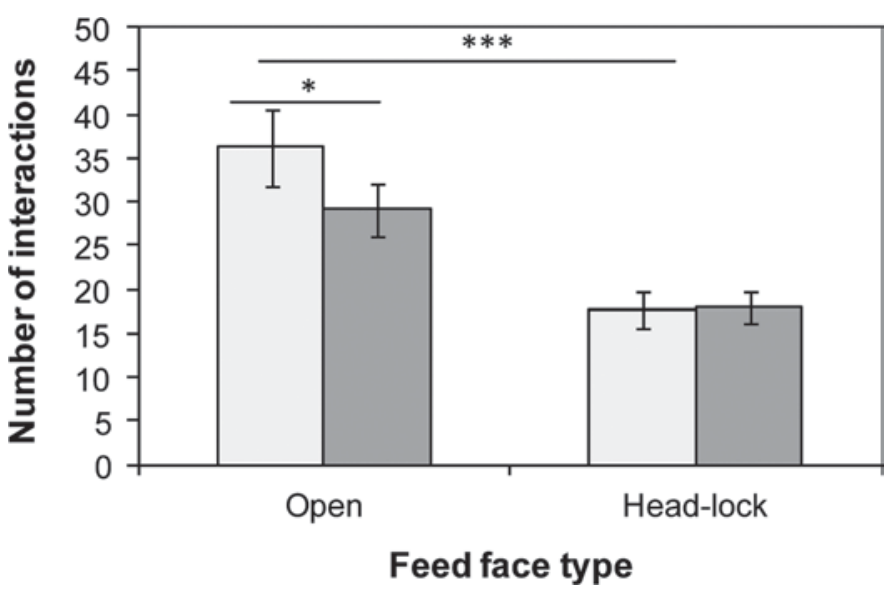

Figure 2. The mean $( \pm \mathrm{SE})$ number of aggressive interactions in $60 \mathrm{~min}$ of observations (taken during the first $90 \mathrm{~min}$ post-time zero) for feed-bunk face type and farm type. Organic farms are shown in the white bars and conventional farms in the gray bars. Number of aggressive interactions differed by feed-bunk face (Wald $=21.1, P<0.001$ ). On farms with open feed-bunk faces, number of aggressive interactions differed by farm type (Wald $=3.85, P<0.05)$. * Indicates significance at $P<0.05 ; * * *$ indicates significance at $P<0.001$. 


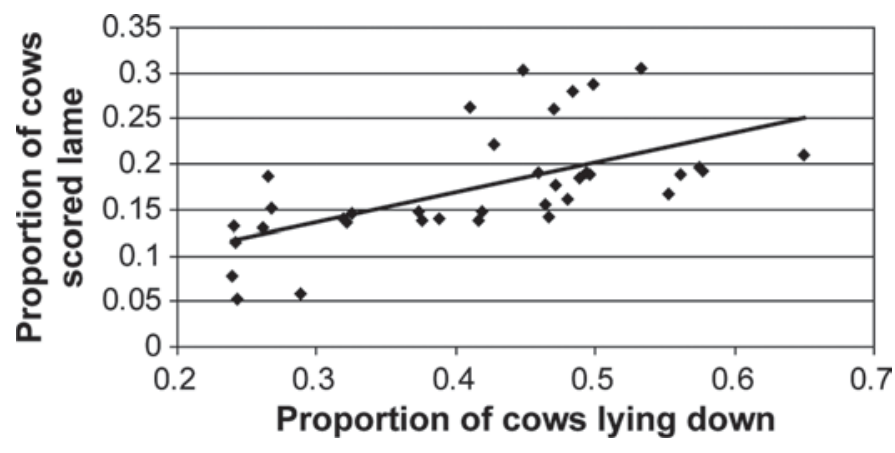

Figure 3. The correlation between the total proportion of cows lying down and the proportion of cows scored lame in a herd (regression line $\left.\mathrm{R}^{2}=55.3, P<0.01\right)$.

types with larger lying areas (cantilever or loop type $=$ $0.44 \pm 0.09$, Newton-Rigg type with back rail reaching curb $=0.27 \pm 0.08$, Wald $=14.17 ; P<0.001$ ) were associated with greater proportions of cows lying down. When standing areas available in alleyways were less than $4.1 \mathrm{~m}^{2} /$ cow (first quartile), the mean proportion of cows standing in alleyways was lower than when standing area exceeded $5.6 \mathrm{~m}^{2} /$ cow (third quartile; 0.08 $\pm 0.01 \mathrm{v} 0.14 \pm 0.02$, Wald $=4.44 ; P<0.05)$.

When housing types were analyzed separately, farm type differences in behavior were observed. On organic farms with freestalls, smaller proportions of cows were lying down in the bedded areas than on conventional farms (organic $=0.38 \pm 0.09$, conventional $=0.43 \pm$ 0.07 , Wald $=6.38 ; P<0.01$ ), whereas a greater proportion of cows on organic farms were active in the alleyways (organic $=0.13 \pm 0.03$, conventional $=0.08$ \pm 0.02 , Wald $=7.00 ; P<0.01$ ).

Herd-level lameness was correlated with median proportion of cows lying down over the 2.5 -h period $\left(\mathrm{R}^{2}=\right.$ 55.3, $P<0.01$; Figure 3).

\section{Comfort Indices}

Stall occupancy was the only cow comfort index to differ between organic and conventional farms, with conventional farms having a higher stall occupancy than organic farms (organic $=44.7 \pm 4.3 \%$, conventional $=56.5 \pm 5.9 \%$, Wald $=4.91 ; P<0.05)$. Cow comfort index $($ organic $=72.3 \pm 5.5 \%$, conventional $=$ $71.4 \pm 6.2 \%$ ), stall use index (organic $=54.2 \pm 3.1 \%$, conventional $=58.6 \pm 3.5 \%$ ), and stall perching index $($ organic $=11.0 \pm 0.6 \%$ conventional $=13.0 \pm 0.9 \%)$ did not differ between farm type $(P>0.05)$.

\section{DISCUSSION}

Overall, these data suggest little difference in the behavior of cows on organic farms compared with cows on conventional farms. Two measures of the results provide evidence that Holstein-Friesian cattle on organic farms may experience hunger to a degree that it affects their behavior. The first of these was the higher proportion of cows feeding during peak feeding time. The pattern of feeding was very similar across farm type (Figure 1), with a large proportion of the herd engaged in feeding over the first 80 to $100 \mathrm{~min}$, decreasing to around $30 \%$ of the herd for the rest of the observation period. The farm type difference over the first 7 scans indicates some difference in feeding motivation between cows on organic farms and cows on conventional farms, which led to increased numbers of cows at the feed-bunk face on organic farms. This may be due to the difference in "quality" of the food provided (Thompson, 2008). Cows on organic farms under European regulations are fed a maximum of $40 \%$ of their diet as concentrates, whereas cows on conventional farms are often fed $50 \%$ of their diet as concentrate at peak yield (Agnew et al., 1998). In a comparison of management practices between organic and conventional farms, the ME of the silage, the maximum daily amount of concentrates given, and the concentrates fed per cow lactation were all lower on organic farms than on conventional farms (Langford et al., 2009). Therefore, it is likely that the cows on organic farms were not provided with as much energy from concentrates and silage in the feed as the conventional cows and may be hungrier after milking. This is supported by data showing that cows from organic farms from the same study farms were marginally more likely to have milk BHBA levels suggestive of subclinical ketosis (Rutherford et al., 2009b) even though BCS did not differ between cows from organic and conventional farms. Other studies have found no clinical evidence for health problems at reduced concentrate feeding percentages on organic farms; however, they did not test for subclinical conditions, nor did they observe behavior (Sehested et al., 2003).

Additionally, the analysis of aggressive interactions provides more evidence for the suggestion that cows on organic farms were hungrier during the first $90 \mathrm{~min}$ after the arrival of new food. Although all cows showed more aggression in the open type feed-faces than in the head-lock type barriers (Endres et al., 2005), cows on organic farms showed more aggression at open feedbunk faces than cows on conventional farms. The result in the open feed-bunk faces may be partly due to the organic farms having a greater proportion of cows at the feed-bunk face overall during peak feeding than the conventional farms. The difference between feedbunk face types merely shows that cows will perform aggressive behaviors when they are able, because the head-locks restrict the performance of these behaviors (Endres et al., 2005). Introduction of head-lock type feed-bunk faces on organic farms may reduce the oc- 
currence of aggressive behavior and allow cows to feed with lowered levels of aggression.

It is possible that the difference between behavior on organic and conventional farms may be heightened now that the derogation in the feeding allowance has been removed. During the time of the study (2004-2006) organic farmers in the UK were working toward the target of $100 \%$ organic feedstuffs, but were still using nonorganic protein in the concentrate feed. Understanding the underlying causes of these behaviors can help farmers use management practices to minimize aggression. Careful choice of genetic merit for milk production (Rozzi et al., 2007) and feeding practices (Thompson, 2008) on organic farms would be methods to reduce hunger within their cow population.

Most variation seen in nonfeeding behavior was explained by housing type rather than by differences between organic and conventional farms. The farms were highly variable in freestall quality, alleyway space, and shape, and there was substantial overlap in size and space of resources between the farm types. When considered separately, behavior did not differ between cows of organic and conventional straw-housed farms. Conversely, on the freestall farms, lying and active behaviors varied with organic-conventional status during the $2.5 \mathrm{~h}$ after peak feeding. Over the whole time period, most cow comfort indices did not show farm type differences, but stall occupancy was higher on conventional farms than organic farms. Interestingly, the strongest association with lying behavior was the herd-level lameness prevalence. Farms that had higher levels of lameness had greater proportions of cows lying down in the 2.5-h recording period. Freestall quality varied widely between farms (Langford et al., 2009), which may affect the proportion of cows lying down. This suggests that cow comfort indices may be measuring the multifactorial motivation to lie down, including both pain and comfort, and teasing out the underlying relations between lying, comfort, and pain would have to be undertaken on a farm-by-farm basis (Ito et al., 2009). It is possible that differences in lying bout length, circadian distribution of lying, or measurements of motivation to lie down may provide more understanding of the associations between lying, comfort, and pain (Jensen et al., 2005).

\section{CONCLUSIONS}

This study yielded 2 main findings. First, it provided evidence for increased motivation to feed during peak feeding and increased attempts to gain access to, or remain at, the feed-bunk face in cows on organic farms compared with cows on conventional farms. This may be indicative of increased hunger in high genetic merit cows being fed organic feedstuffs at the roughage:concentrate DM ratio of 60:40 as required under European regulations. The possibility that cows on organic farms exhibit hunger may require a more systems-based approach to alleviate the condition. The second main finding is that farm housing type affected dairy cow behavior more than whether the farm was organic or conventional. Most variation in dairy cow behavior was explained by being housed either in straw pens or freestall barns. When freestall barns were considered separately, the type and quality of the stalls available to the cows affected their behavior. Conventional farms had better freestalls than organic farms, and greater proportions of cows on conventional farms were lying down after peak feeding. Lameness prevalence correlated with lying behavior, suggesting that the proportion of cows lying down was affected by both pain and comfort.

\section{ACKNOWLEDGMENTS}

We thank all farmers for their participation in this study. The project was funded by the UK Department for the Environment, Food and Rural Affairs (Defra, London, UK). We thank the following organizations for access to their farmer membership lists: The Soil Association (Bristol, UK), Organic Milk Suppliers CoOperative (Worle, Somerset, UK), Scottish Organic Producers Association (Edinburgh, UK), and Kingshay Farming Trust (Glastonbury, UK). Statistical advice was provided by Ian Nevison, of Biomathematics and Statistics Scotland (BioSS, Edinburgh, UK).

\section{REFERENCES}

Agnew, R. E., T. Yan, and F. J. Gordon. 1998. Nutrition of the high genetic merit dairy cow-Energy metabolism studies. Pages 181208 in Recent Advances in Animal Nutrition. P. C. Garnsworthy and J. Wiseman, ed. Nottingham University Press, Nottingham, UK.

CEC (Commission of the European Communities). 2004. Consolidated text (01/05/04) of Council Regulation No 2092/91 on organic production. Off. J. L198:1-15.

Cook, N. B., T. B. Bennett, and K. V. Norland. 2005. Monitoring indices of cow comfort in free-stall-housed dairy herds. J. Dairy Sci. 88:3876-3885.

Endres, M. I., T. J. DeVries, M. A. G. von Keyserlingk, and D. M. Weary. 2005. Effect of feed barrier design on the behavior of loosehoused lactating dairy cows. J. Dairy Sci. 88:2377-2380.

Harper, G. C., and A. Makatouni. 2002. Consumer perception of organic food production and farm animal welfare. Br. Food J. 104:287-299.

Hovi, M., A. Sundrum, and S. M. Thamsborg. 2003. Animal health and welfare in organic livestock production in Europe: Current state and future challenges. Livest. Prod. Sci. 80:41-53.

Huzzey, J. M., T. J. DeVries, P. Valois, and M. A. G. von Keyserlingk. 2006. Stocking density and feed barrier design affect the feeding and social behavior of dairy cattle. J. Dairy Sci. 89:126-133.

Ito, K., D. M. Weary, and M. A. G. von Keyserlingk. 2009. Lying behavior: Assessing within- and between-herd variation in free-stallhoused dairy cows. J. Dairy Sci. 92:4412-4420.

Jensen, M. B., L. J. Pedersen, and L. Munksgaard. 2005. The effect of reward duration on demand functions for rest in dairy heifers 
and lying requirements as measured by demand functions. Appl. Anim. Behav. Sci. 90:207-217.

Langford, F. M., K. M. D. Rutherford, M. C. Jack, L. Sherwood, A. B. Lawrence, and M. J. Haskell. 2009. A comparison of management practices, farmer-perceived disease incidence and winter housing on organic and non-organic dairy farms in the UK. J. Dairy Res. 76:6-14.

Rozzi, P., F. Miglior, and K. J. Hand. 2007. A total merit selection index for Ontario organic dairy farmers. J. Dairy Sci. 90:15841593.

Rutherford, K. M. D., F. M. Langford, M. C. Jack, L. Sherwood, A. B. Lawrence, and M. J. Haskell. 2008. Hock injury prevalence and associated risk ractors on organic and non-organic dairy farms in the United Kingdom. J. Dairy Sci. 91:2265-2274.

Rutherford, K. M. D., F. M. Langford, M. C. Jack, L. Sherwood, A. B. Lawrence, and M. J. Haskell. 2009a. Lameness prevalence and risk factors in organic and non-organic dairy herds in the United Kingdom. Vet. J. 180:95-105.

Rutherford, K. M. D., F. M. Langford, M. C. Jack, L. Sherwood, A. B. Lawrence, and M. J. Haskell. 2009b. Organic dairy cow management and indicators of energy balance. Vet. Rec. 165:147-148.
Sehested, J., T. Kristensen, and K. Søegaard. 2003. Effect of concentrate supplementation level on production, health and efficiency in an organic dairy herd. Livest. Prod. Sci. 80:153-165.

Sundrum, A. 2001. Organic livestock farming-A critical review. Livest. Prod. Sci. 67:207-215.

Thompson, M. T. 2008. The nutritional challenges of dairy cows under organic standards. Cattle Pract. 16:44-49.

Vaarst, M., S. Padel, M. Hovi, D. Younie, and A. Sundrum. 2005. Sustaining animal health and food safety in European organic livestock farming. Livest. Prod. Sci. 94:61-69.

Weller, R. F., and P. J. Bowling. 2000. Health status of dairy herds in organic farming. Vet. Rec. 146:80-81.

Yiridoe, E. K., S. Bonti-Ankomah, and R. C. Martin. 2005. Comparison of consumer perceptions and preference toward organic versus conventionally produced foods: A review and update of the literature. Renewable Agric. Food Syst. 20:193-205. 